\title{
Characterisation of Electric Current Treated Austenite using Misorientation Angle Distributions in Martensite
}

\author{
Osamudiamen Omoigiade ${ }^{1}$, Arunansu Haldar ${ }^{2}$, and Rongshan Qin ${ }^{1,3}$ \\ ${ }^{1}$ Department of Materials, Imperial College London Exhibition Road, London SW7 2AZ, UK \\ ${ }^{2}$ TATA Steel Swinden Technology Centre, Moorgate, Rotherham S60 3AR, UK \\ ${ }^{3}$ Department of Engineering IE Innovation, The Open University, Milton Keynes MK7 6AA, UK
}

\begin{abstract}
The angle misorientation distribution of martensite formed from electric current treated and nontreated austenite samples are studied using electron backscatter diffraction. The electric currents are pulsed with loading width of $80 \mu \mathrm{s}$, at a frequency of $100 \mathrm{~Hz}$ and current density of $4.21 \mathrm{~A} / \mathrm{mm}^{2}$ supplied by a DC Voltage. The majority of angle misorientations are $<5^{\circ}$ and exist within the martensite grains, while only minority of all misorientations are derived from the prior austenite grain boundary and were found to lie in the range $20-50^{\circ}$. Distinct textures develop in both electric current treated and non-treated samples with increased quenching temperature. Analysis of the prior austenite show reduced grain sizes in the electric current treated samples at all quenching temperatures considered.
\end{abstract}

Keywords: Martensite; Phase transformation; Misorientation Angle Distributions; Electropulsing; Austenite; Plain Carbon Rod. 


\section{Introduction}

Originally, research in electric current treatment of metals focused on its influence on mechanical deformation [1] from which the term 'electroplasticity was coined', but with time the technique evolved to include microstructural studies [2-8]. Electroplasticty theory [9] associates the enhanced plasticity exhibited by metals with the increased mobility of dislocations by a flow of electrons stimulating dislocation propagation. These dislocation-electron interactions were extended to explain changes in microstructures subjected to electric current treatment through a so called 'electron wind' effect [2]. However subsequent calculations have suggested that the force generated by the electron wind is insufficient [10] to be solely responsible for the observed microstructural and mechanical phenomenon such as grain refinement [2] and increased plasticity [9]. There is moreover some consensus in-line with this, within the scientific community concerned with this area of research.

Thermodynamic theories for electric current treatment of metals predict a contribution to Gibbs energy that can constitute a phase change $[8,11,12]$, but understanding its influence on transformation kinetics has proven challenging [13]. A complete thermodynamic-kinetic theory is required in order enable design of tailored microstructures, a task achievable by adquate experimentation. While electric current driven microstructure research on engineering alloys have included precipitation [14,15], recrystallisation $[2,16]$, grain growth $[3,5]$ and texture evolution [17-20] there have been no reports on angle misorientations. Angle misorientations reveal microstructurally critical information beyond textures, providing history of prior phases such as austenite which shares an invariant plane with the product phase martensite formed upon quenching. The ability to trace the development of phases between parent and product will help extend this to metal processes requiring phase transformations. This present work employs electron backscattering diffraction (EBSD) to characterise martensite, and forms part of a comprehensive study of the influence of electric current treatment on plain carbon steels that will be reported elsewhere.

\section{Experimental}

\subsection{Materials Processing}

Plain carbon steel $5.5 \mathrm{~mm}$ rods of composition (in wt.\%) Fe-0.83C-0.51Mn-0.2Si-0.011P-0.005S-0.0036N were rolled out from the wire-rod-mill and cut into $50 \mathrm{~mm}$ lenghts for use in this experiment. Their composition was determined iteratively using inductive coupling mass spectrometry. Then further characterised using differential scanning calorimetry (DSC) to determine the onset of austenite transformation at a cooling rate 
of $1^{\circ} \mathrm{C} / \mathrm{min}$, found to be $731^{\circ} \mathrm{C}$ (see Figure 1). The martensite start temperature was calculated as $217^{\circ} \mathrm{C}$ using an empircal equation [21] for steels having between 0.17 and $1.7 \mathrm{wt. \%} \mathrm{C}$ and total alloying elements $<7$ wt.\%.

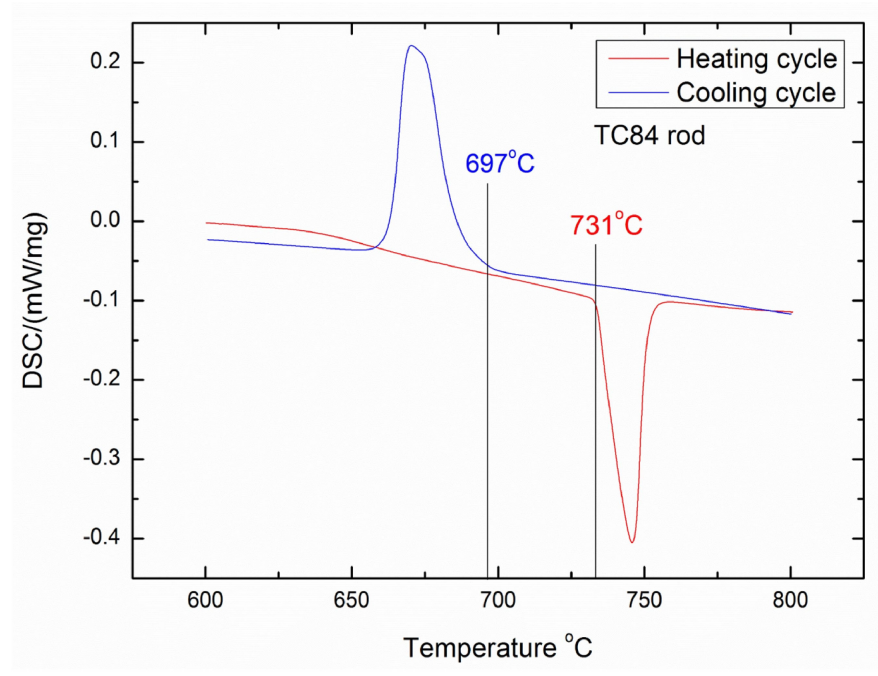

Figure 1: Differential Scanning Calorimetry plot indicating the phase transformations to austenite and pearlite during heating and cooling respectively for the plain carbon steel of composition (in wt.\%) Fe$0.83 \mathrm{C}-0.51 \mathrm{Mn}-0.2 \mathrm{Si}-0.011 \mathrm{P}-0.005 \mathrm{~S}-0.0036 \mathrm{~N}$.

Rods of specified dimension (see Figure 2) were inserted into a tube furnace preheated to 800, 900 and $1000^{\circ} \mathrm{C}$ for 4.5 minutes, followed by a water quench and their temperature profiles were monitored using a type $\mathrm{K}$ thermocouple. The cooling rates were calculated from the experimentally recorded temperatures-time curves using a data analysis software and were found to average at $294 \pm 15^{\circ} \mathrm{C}$, confirming that the cooling rates would unequivocally produce a fully martensitic structure that was thereafter corroborated with EBSD (see Figure 6).

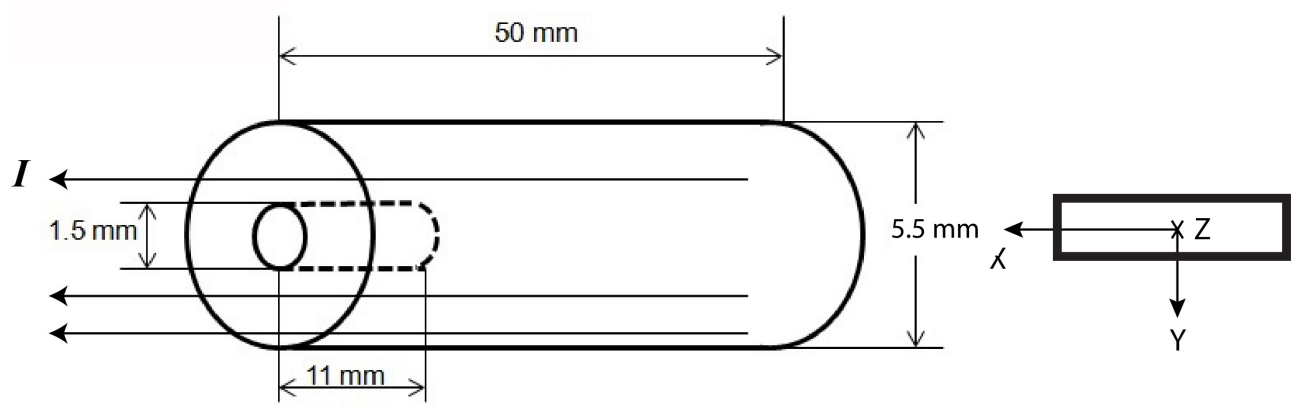

Figure 2: Diagram of drilled $50 \mathrm{~mm}$ long plain carbon rod with the sample orientation indicated, where the $\mathrm{X}-\mathrm{Y}$ plane is the examined region in micrographs and the $\mathrm{Z}$ direction perpendicular to the longitudinal $(\mathrm{X}-\mathrm{Y})$ plane. 
Electric current treated samples undergo identical heat treatment conditions with copper wires attached at both ends to supply a pulsed current over the austenitisation period (see Figure 3). The pulses are approximated by square waves, each pulsed with a loading width of $80 \mu s$, delivered at a frequency of $100 \mathrm{~Hz}$ and current density of $4.21 \mathrm{~A} / \mathrm{mm}^{2}$ conducted along the $\mathrm{X}$ axis of the rod. There was moreover no observable increase in temperature for samples with electric current passing through them at elevated temperatures during heat treatment.

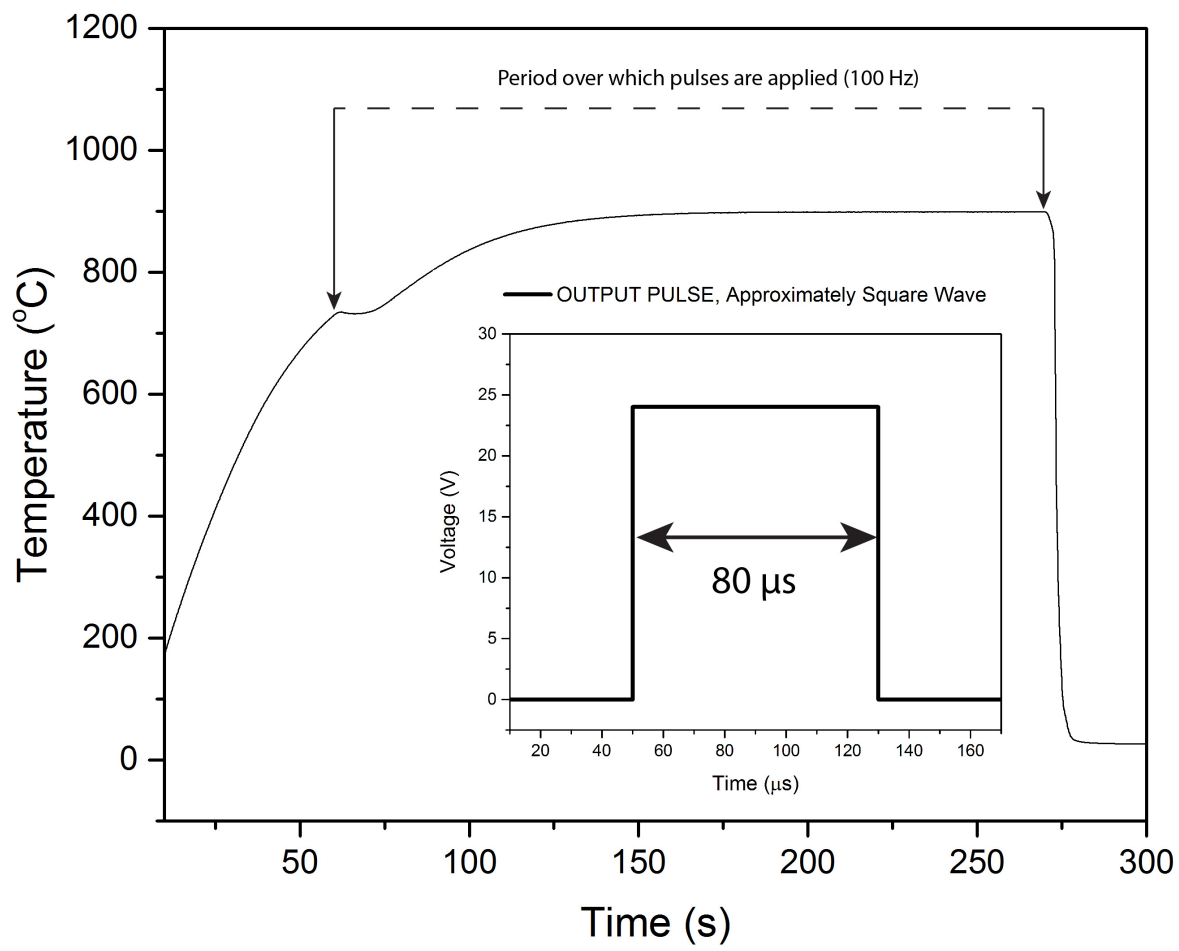

Figure 3: Example temperature profile detailing period at which current was applied.

\subsection{Microstructural Characterisation}

Treated samples underwent standard metallographic preparation to achieve smooth, strain free surfaces required for EBSD characterisation. The surfaces were finished with a 1 hr polish using $30: 70 \mathrm{H}_{2} \mathrm{O}_{2}$ to oxide(silicon) polishing suspensions (OPS) mixture. Steels lend themselves well to EBSD characterisation and hence an adequate surface quality for analysis was attainable with this finish. The inspected surface of each sample is in the longitudinal plane, defined as lying in the $\mathrm{X}-\mathrm{Y}$ plane and normal to the $\mathrm{Z}$ direction (Figure 2).

The microscope used in this investigation is the Zeiss Auriga Cross Beam, which features a Schottky field emission Gemini electron column fitted with a high brightness $\mathrm{LaB}_{6}$ filament capable of resolutions of 1.0 $\mathrm{nm}$ at $15 \mathrm{kV}$ accelerating voltage and a detector tilt of $3.5^{\circ}$, and can measure angle misorientation to an 
accuracy of $1 \times 10^{-3}$. Given the Auriga's resolution is sufficiently adequate for step sizes of $390 \mathrm{~nm}$ used for this analysis, the accelerating voltage was raised to $20 \mathrm{kV}$ to increase intensity of detected back scattered electrons to achieve high imaging quality in the generated EBSD maps of 150 by $200 \mu \mathrm{m}$. The scan grid encompasses 584 by 312 pixels, and martensite grains are defined as having 5 pixels and disorientation between them of $<5^{\circ}$, above which a new grain will be defined. The martensite laths were indexed using bcc ferrite and their textures were calculated using ESPRIT 2.0, a commercial software. In these size maps, obtained for each of the individually analysed samples the approximate number of martensite laths were 5500. Two kinds of misorientation distributions are considered: correlated, which compares misorientation between nearest neighbour indexed points; and uncorrelated, an indexed point in comparison to every other indexed point on the map. Post-processing was carried out using the Bruker ESPRIT software, which forms part of the Quantax EBSD system.

\subsection{Prior Austenite Grain Size Measurement}

Measurements of the prior austenite grain sizes have been conducted using the average diameter of a circumbscribed polygon. Two example measurements are constructed in Figure4. In addition, calculations of the prior austenite grain size have been made using a method developed by Morales-Rivas [22].

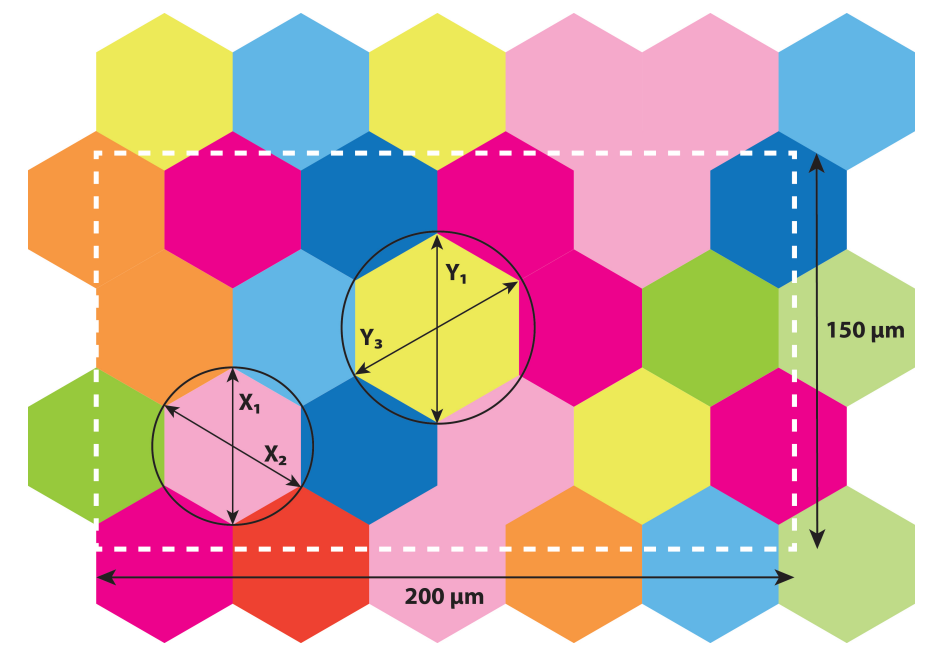

Figure 4: Illustrated EBSD map, where the grain size is estimated by taking three diametric measurements of grains within the observed region, from which an average is found.

This method utilises a two step calculation, involving the automatic computation of a distance disorientation function, which is defined here as the misorientation distribution between pixels over increasing distances. Initially, the angle distribution is characteristic of the Kurdjumov-Sachs orientation relationship between austenite and martensite as the pixels considered lie in the same prior austenite grain [22]. However 
for increasing distances, misorientation between pixels belonging to relatively far apart prior austenite grains are assessed and the distribution function tends towards a Mackenzie-Handscomb Distribution (hereinafter, Mackenzie) [23, 24]; the rotation applied to restore a randomly misoriented cube about a mutual axis into coincidence with a reference cube. An increasing prior austenite grain size is therefore a corollary of larger minimum distances at which a misorientation distribution tends toward a Mackenzie distribution. The second step of the calculation takes the residual sum of squares between the Mackenzie distribution and the calculated misorientation distribution at increasing distances such that it tends towards a minimum at a given distance defined as the estimated grain size (EGS). Although EGS was originally proposed by Brahme [25], a variant of this parameter is utilised here in accordance with the work conducted by Morales-Rivas. Her approach mitigates for the discrepancy that arises from duplicity i.e. distributions of similar intensities but dissimilar angles possessing identical RSS values as it does not work with the method employed here. The RSS minimum value, from which EGS is determined is taken to be $5 \times 10^{-4}$ illustrated by the dotted line in Figure 5B. The prior austenite grain size is approximately $1.15 \times$ EGS [22].

The size of micrographs displayed in this paper are of dimension 200 by $150 \mu \mathrm{m}$, however RSS calculations were made using larger micrographs over extended lengths in the instances where the distributions did not tend toward a Mackenzie distribution using 200 by $150 \mu \mathrm{m}$ micrographs.
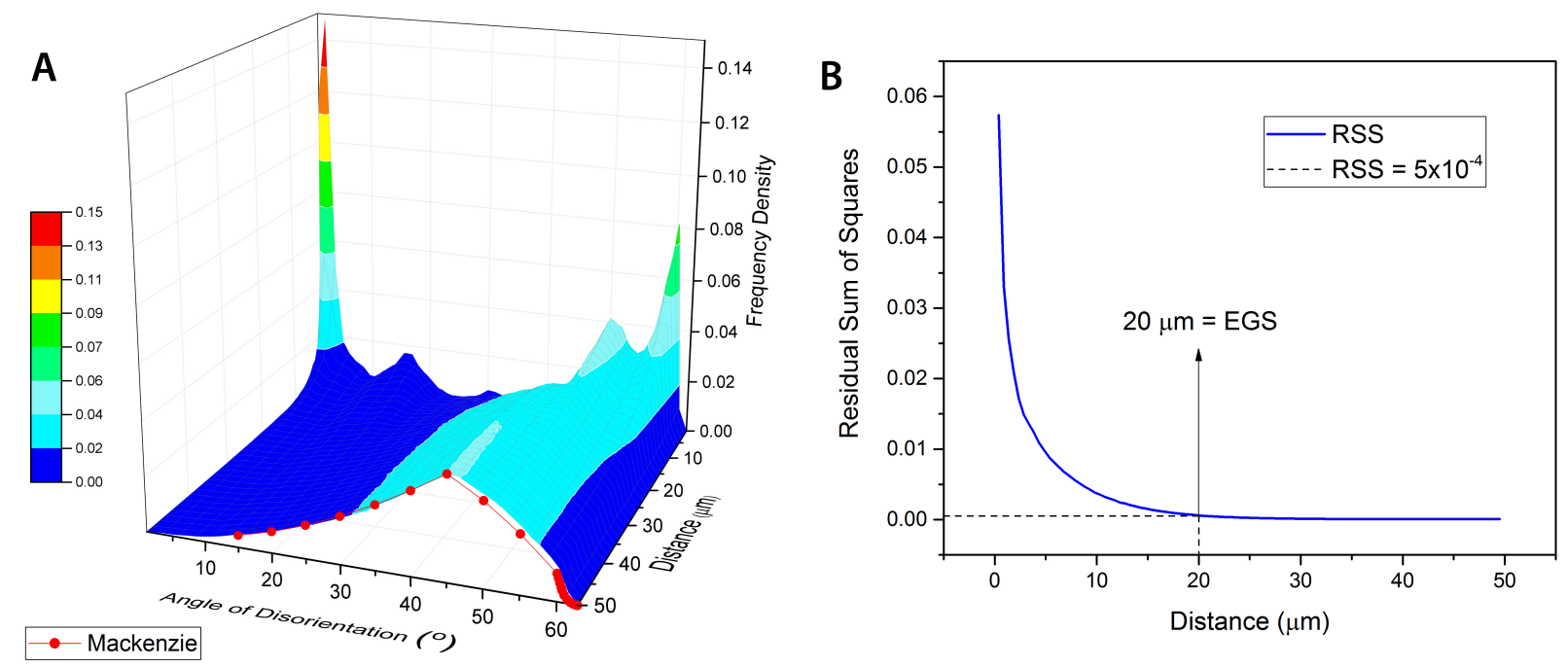

Figure 5: (A) The distance disorientation plot for martensite formed by quenching austenite at $800^{\circ} \mathrm{C}$ tends toward a Mackenzie distribution at sufficiently large distances. (B) Estimated grain size (EGS) is obtained at the distance where Residual sum of Squares (RSS) is $20 \mu \mathrm{m}$. 


\section{Results}

\subsection{Martensite Microstructure}

The secondary electron micrograph in Figure 6 is from a representative region of the sample electropulsed at $1000^{\circ} \mathrm{C}$. It shows a fully martensitic microstructure. Although a few grains are quite large and nonlenticular shaped. Those indicated by red dots on the micrograph may initially be mistaken for retained austenite but further indexing of face centred cubic iron returned a near null value. The large grains were indexed as body centred cubic (therefore martensite). A measurement of the angle of misorientation inside those non-lenticular grains using the ESPRIT software showed a distribution of low angle boundaries of $<3^{\circ}$, suggestive of a coalesced martensite [26] and reinforced by a gradient across the grain of $\sim 0.25^{\circ} \mu m^{-1}$ see Figure 7. There was no apparent change in the distribution of coalesced martensite among samples.
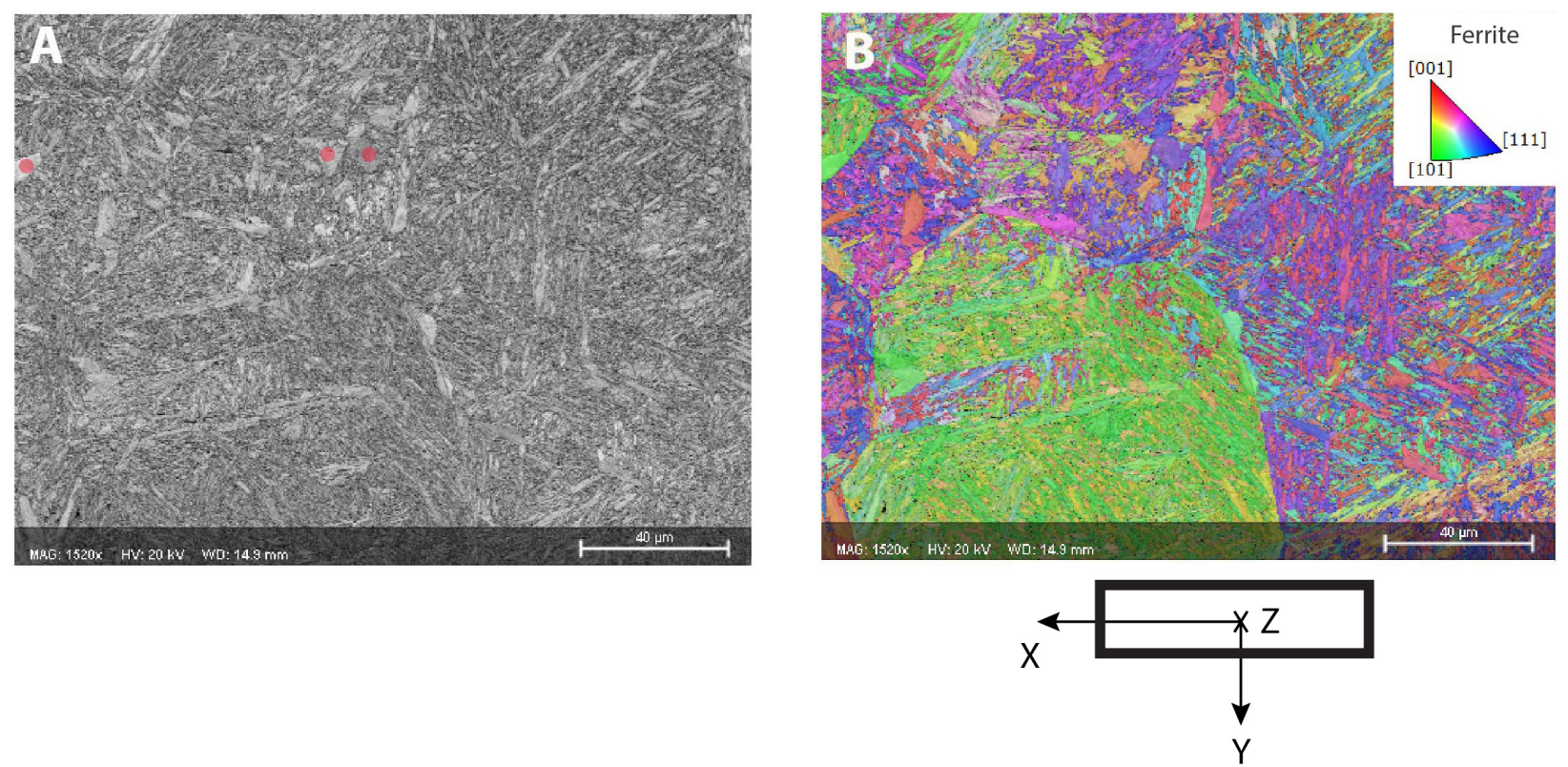

Figure 6: (A) Secondary electron image of martensite formed in the steel rods when treated with electric current and quenched from $1000^{\circ} \mathrm{C}$. (B) EBSD map of the same region, coloured according to Inverse-Pole Figure oriented with respect to the $\mathrm{Z}$ direction (IPF-Z). Where the $\mathrm{Z}$ direction is normal to the plane of observation in the sample as indicated by the rod schematic below the EBSD map. Coalesced Martensite grains indicated in (A) are apparent by the uniformity of the designated IPF-Z colour mapping. 

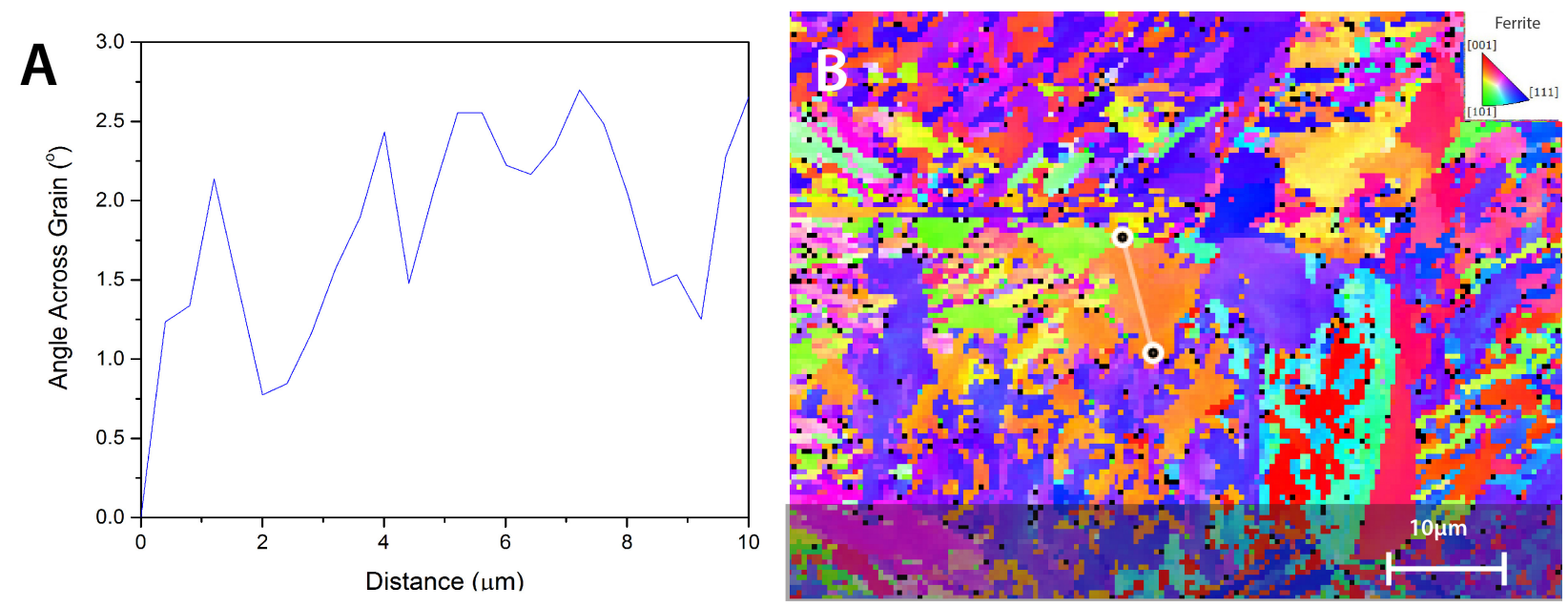

Figure 7: (A) Boundary angle distribution relative to the angle of the first point measurement begins from across a (B) non-lenticular martensitic grain in a sample treated with electric current and quenched from $1000^{\circ} \mathrm{C}$.

The average martensite lath for each micrograph was calculated based on the square root of the area occupied by the pixels allocated to each grain from an average of 5500, so that they are of statistical significance. Though some discrepancy exists concerning the lower aspect ratio of a martensite lath in comparison to a square. The Bruker ESPRIT software computed similar martensite grain sizes across all samples with the average grain size in the region of $5 \mu \mathrm{m}$. The sample cooling rates were calculated as the gradient of the slope from $9 / 10^{t h^{\prime} s}$ of the austenitisation temperature to $200^{\circ} \mathrm{C}$.

\subsection{Angle Misorientation Distribution}

An uncorrelated misorientaion distribution is generated for each of the treatment conditions considered and is shown in Figure 8. The data explicitly illustrates the deviation of misorientation distributions in martensite from a Mackenzie (random) distribution as defined for cubic material between angles 0 and $62.80^{\circ}[23]$. Hence, highlighting the degree of randomness of the observed microstructure for each treatment condition. It is apparent that both samples quenched from $800^{\circ} \mathrm{C}$ exhibit near ideal randomness. This suggests that the sample area $200 \times 150$ microns is sufficiently large to extract representative data concerning martensite misorientations for the material, hence providing insight to long range average properties, such as prior austenite grain size which can be calculated from the martensite orientation distributions $[22,27]$. As the temperature increases however, the misorientation distribution deviates from random and becomes particularly prominent at $1000^{\circ} \mathrm{C}$. This deviation is flagrant when a Mackenzie distribution is juxtaposed against the measured misorientation distributions (Figure 8) as the single peak observed in samples quenched from $800^{\circ} \mathrm{C}$ shifts towards higher angles for samples quenched from $1000^{\circ} \mathrm{C}$; from $45^{\circ}$ to $\sim 53^{\circ}$. 

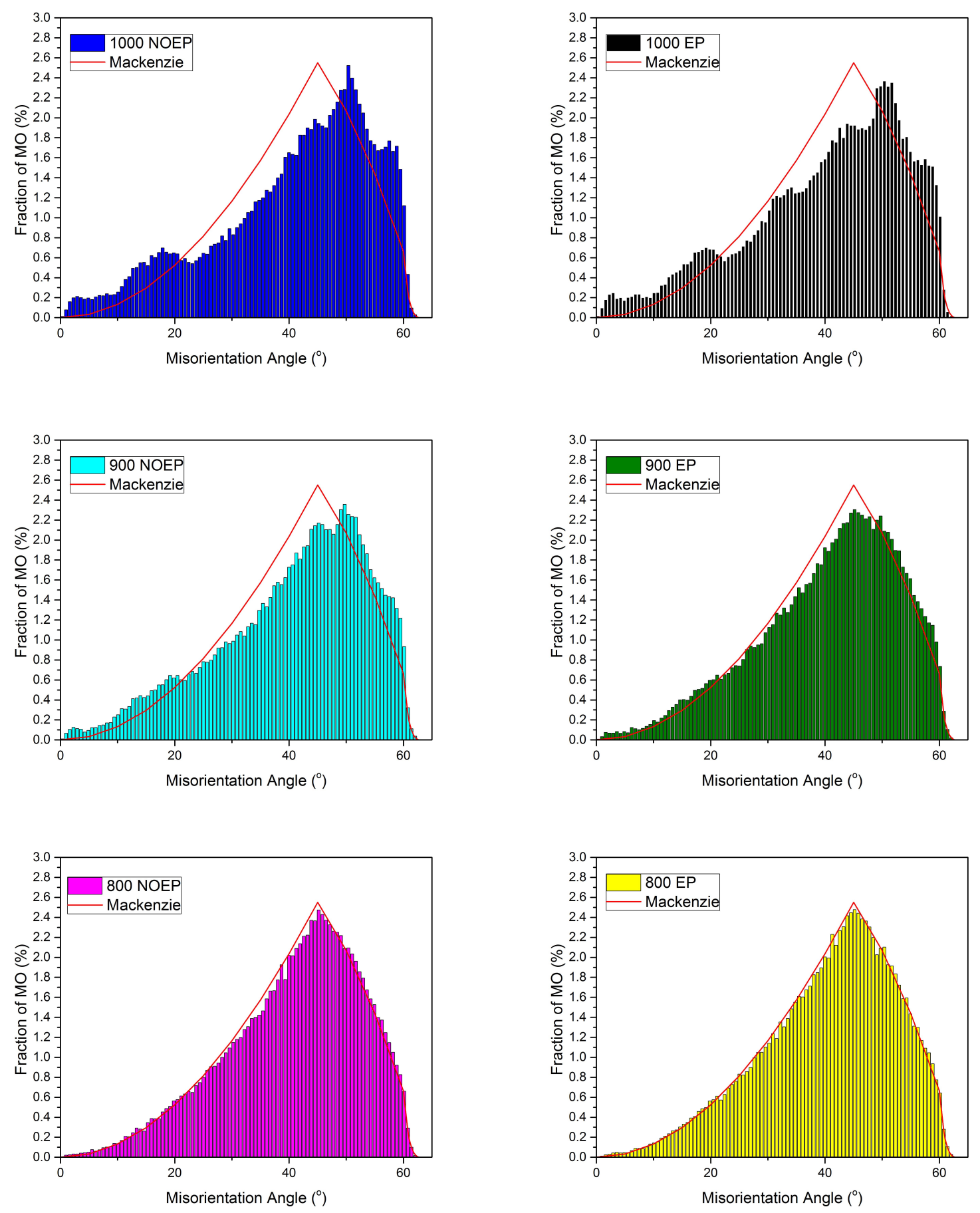

Figure 8: Uncorrelated misorientation distribution of points indexed martensite when quenched from A, B: $1000^{\circ} \mathrm{C} ; \mathrm{C}, \mathrm{D}: 900^{\circ} \mathrm{C} ; \mathrm{E}, \mathrm{F}: 800^{\circ} \mathrm{C}$ with prior electric current treatment (EP) and without (NOEP).

The correlated angle misorientation distribution, or nearest neighbour misorientations is plotted in Figure 9A for all the pixels in the EBSD map presented in Figure 9B. The misorientations associated with the 
prior austenite grain boundaries have been isolated and inset in the same figure. Misorientations which formed on austenite transforming to martensite, account for approximately $9 / 10^{t h^{\prime}} s$ of all adjacent neighbour misorientations, with $5 / 6^{t h^{\prime}}$ s of these boundaries being, $<5^{\circ}$ as shown in Figure $9 \mathrm{~A}$ and the remaining $1 / 6^{t h}$ being $>50^{\circ}$. The smallest fraction of angle misorientations were in the range $20-50^{\circ}$ and were attributable to prior austenite grain boundaries and accounted for $1 / 10^{\text {th }}$ of all adjacent neighbour misorientations. The Esprit software's post-processing options were used to render selected boundaries by misorientation angle between $20-50^{\circ}$ and are indicated by dark lines as seen in Figure 9B. Some lines are broken due to unsuccessfully indexed pixels but the outline traced unequivocally displays the prior austenite grain boundary.
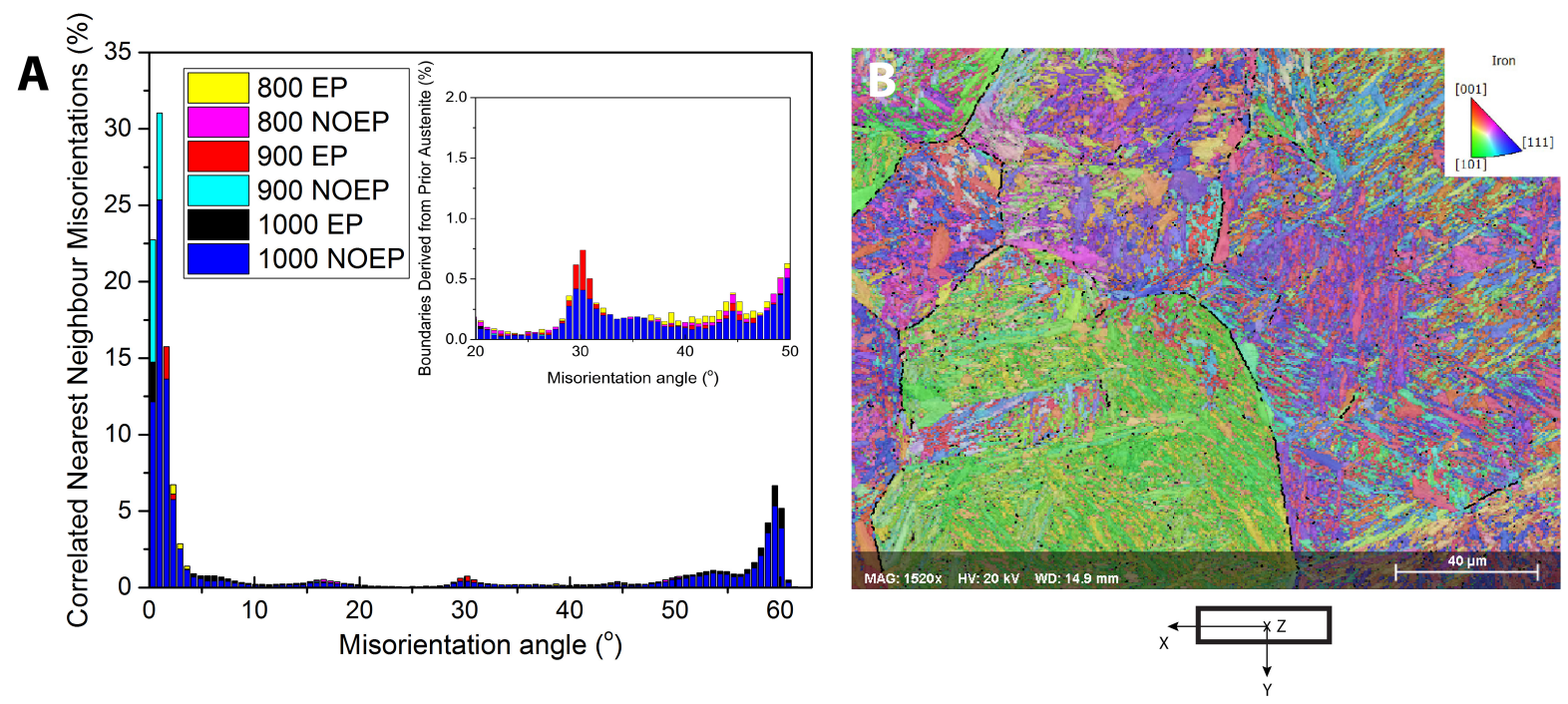

Figure 9: (A) Correlated misorientation distributions of indexed points in martensite grains, and inset: Misorientation angles associated with the prior austenite grain boundary. (B) EBSD map, coloured according to Inverse-Pole Figure (IPF) oriented with respect to $\mathrm{Z}$ direction; as indicated by the rod and axes schematic below the map. For electric current treated sample quenched from $1000^{\circ} \mathrm{C}$ with reconstructed prior austenite grain boundaries; indicated by dark lines.

\subsection{Martensite Texture}

Texture development with temperature and electric current treatment is presented in the pole figures shown in Figure 10. At lower quenching temperatures, the textures are determined from a sufficiently long range; indicated by the revealed Mackenzie distribution for Figure 8E and F, suggesting that the observed region contains long range information on the sample. The pole figures in Figure 10E shows relatively high intensities of crystallographic planes distributed randomly in-plane (of observersation). The 110 are oriented in the $+\mathrm{Y}$ direction, 100 oriented in $+\mathrm{Y}$ and $-\mathrm{Y}$ and 111 oriented $45^{\circ}$ between the $+\mathrm{X}, \mathrm{Y}$ and $-\mathrm{X}, \mathrm{Y}$. However in the case of the electric current treated sample Figure 10F the multiples of a random distribution (MRD) 
(indicated on the intensity bar in each map), parallel to the spacial direction $\mathrm{Z}$ axis and for crystallographic planes other than 100, texturing appears relatively weak. For 100 the $+\mathrm{X}$ and $-\mathrm{X}$ shows the strongest texture in this sample, and this axis is parallel to the direction of the applied current.

At higher temperatures, 900 and $1000^{\circ} \mathrm{C}$ deviate from random as indicated by the increasing range of MRD [28] given in Figure 10, where a number closer to 1 suggests a more random distribution. The pole figure for the non-electric current treated sample quenched from $1000^{\circ} \mathrm{C}$ Figure $10 \mathrm{~A}$ reveals a distinct texture, which however is not as pronounced in the electric current treated structure. Similarly, for samples quenched from $900^{\circ} \mathrm{C}$ in Figures $10 \mathrm{C}$ and D, where non-electric current treated, D exhibits a more random texture compared to that of $\mathrm{C}$. As temperature increases, the observed textures in martensite become more distinct, though to a lesser extent in those treated with electric current in the prior austenite phase.

\subsection{Prior Austenite Grain Size}

The standard deviation on the measured austenite grain sizes lie within the calculated values, ratifying the reliability of the obtained values, although calculated results are more accurate. The percentage difference is calculated as the reduction from the 'NOEP' condition.

\begin{tabular}{|lcccccc|}
\hline $\begin{array}{l}\text { Name of } \\
\text { Sample }\end{array}$ & EGS & $\begin{array}{c}\text { Calculated } \\
\text { PAGS }\end{array}$ & $\begin{array}{c}\text { \% Calculated } \\
\text { PAGS }\end{array}$ & $\begin{array}{c}\text { Average } \\
\text { Measured PAGS }\end{array}$ & $\begin{array}{c}\% \Delta \text { Measured } \\
\text { PAGS }\end{array}$ & STD \\
\hline 800 EP & 20.0 & 23.0 & $-25.0 \%$ & 22.3 & $-20.3 \%$ & 3.2 \\
800 NOEP & 26.7 & 30.7 & & 28.0 & & 4.6 \\
900 EP & 49.8 & 57.2 & $-25.2 \%$ & 41.7 & $-35.7 \%$ & 2.5 \\
900 NOEP & 66.5 & 76.4 & & 64.8 & & 11.2 \\
1000 EP & 92.0 & 105.8 & $-18.2 \%$ & 67.2 & $-36.3 \%$ & 17.7 \\
1000 NOEP & 112.5 & 129.4 & & 105.4 & & 30.2 \\
\hline
\end{tabular}

Table 1: Measured and calculated prior austenite grain sizes (PAGS) determined from the estimated grain size (EGS), and the standard deviation of the mean (STD) for measured prior austenite grains of electric current treated samples (EP) and none treated (NOEP). 

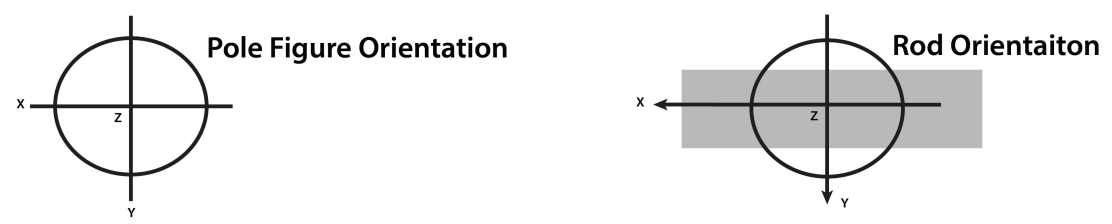

A

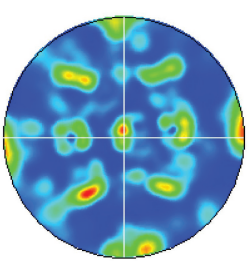

B

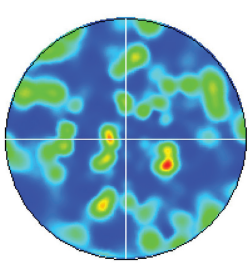

C

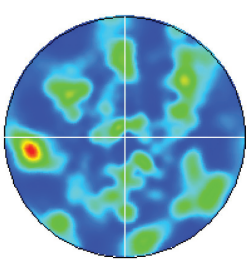

D

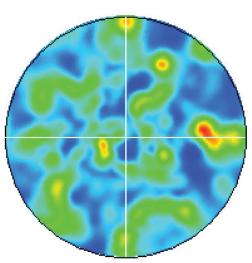

E

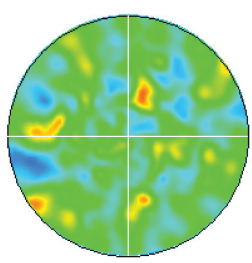

F

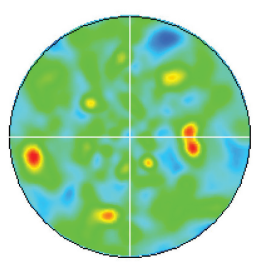

$\{100\}$

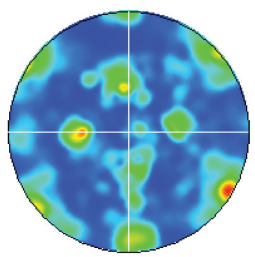

$\{100\}$

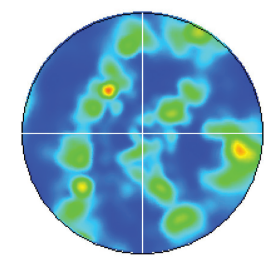

$\{100\}$

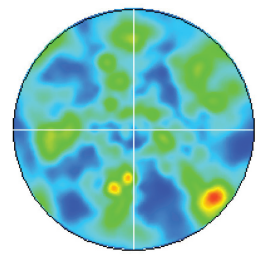

$\{100\}$

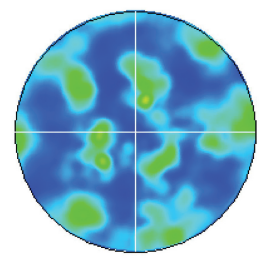

$\{100\}$

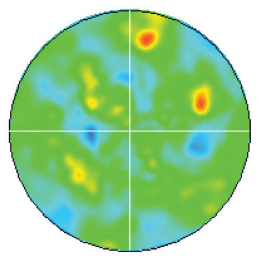

$\{100\}$

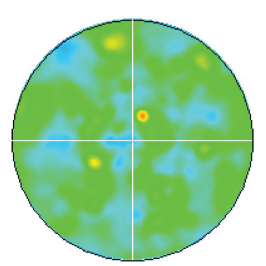

$\{110\}$

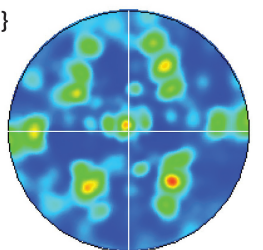

$\{110\}$

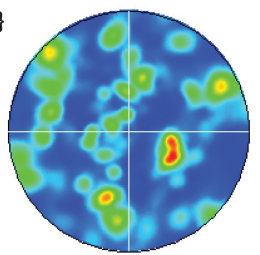

$\{110\}$

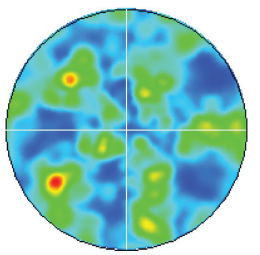

$\{110\}$

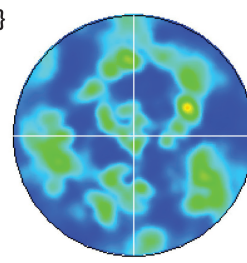

\{110\}

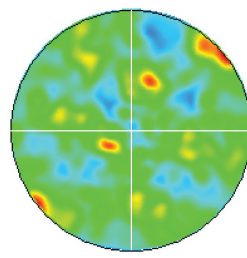

$\{110\}$

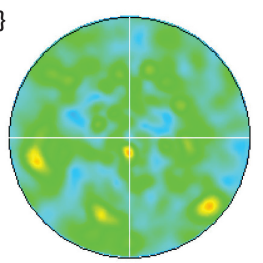

$\{111\}$

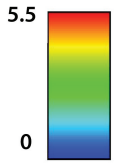

$\{111\}$

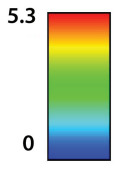

$\{111\}$

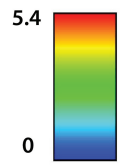

$\{111\}$

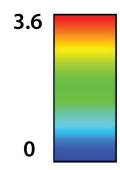

\{111\}

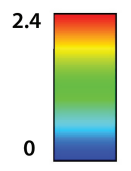

\{111\}

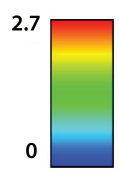

Figure 10: Pole Figures for samples A,C,E have not been treated with electric current and represent descending temperatures respectively $1000^{\circ} \mathrm{C}, 900^{\circ} \mathrm{C}, 800^{\circ} \mathrm{C}$. Samples B, D, F have been treated with electric current and are listed in descending temperature respectively $1000^{\circ} \mathrm{C}, 900^{\circ} \mathrm{C}, 800^{\circ} \mathrm{C}$. 


\section{Discussion}

A 200 by $150 \mu m$ micrograph for a sample quenched from $800^{\circ} \mathrm{C}$ is sufficient to generate a pole figure that is representative of martensite's texture across the material, apparent from the near ideal random distribution shown in Figure 8. It is known that a Kurdjumov-Sachs orientation relationship (or near) exists between the martensite and parent austenite [29]:

$$
\begin{gathered}
\{111\}_{\gamma} \|\{011\}_{\alpha} \\
\langle 10 \overline{1}\rangle_{\gamma} \|\langle 11 \overline{1}\rangle_{\alpha}
\end{gathered}
$$

The corresponding austenite plane to the observed $100_{\alpha}$ texture in the electric current treated sample can be deduced by applying the appropriate rotation matrix to the plane normal. Applying this rotation matrix the $100_{\alpha}$ texture can therefore be approximated to have developed from an austenite $101_{\gamma}$ plane oriented in the direction of the current, i.e. $+\mathrm{X},-\mathrm{X}$ direction. The strong textures are derived from large grains of martensite(see Figure 11) viewed in the micrograph, however the narrower distribution of crystal orientations adopted by larger grains in the electric current treated samples suggests preferential grain formation.

For samples quenched from higher temperatures, relatively strong texturing becomes apparent due to the increasing size of the prior austenite grains with austenitising temperature [22]. Since martensite shares an invariant plane with the parent austenite, the number of martensite variants formed from a single austenite grain is limited [29]. The increase in size of the prior austenite therefore reduces the likelihood of multiplicity or the probability of observing a large number of identical martensite variants. Although micrographs of samples quenched from 900 and $1000^{\circ} \mathrm{C}$ provide microtextural information, their extent of deviation from a uniform random distribution does however offer an indication of the relative sizes of prior austenite grains. Where a distribution in martensite closer to random denotes smaller prior austenite grains, a phenomenon that has been exploited in attaining prior austenite grain size $[22,27]$. 

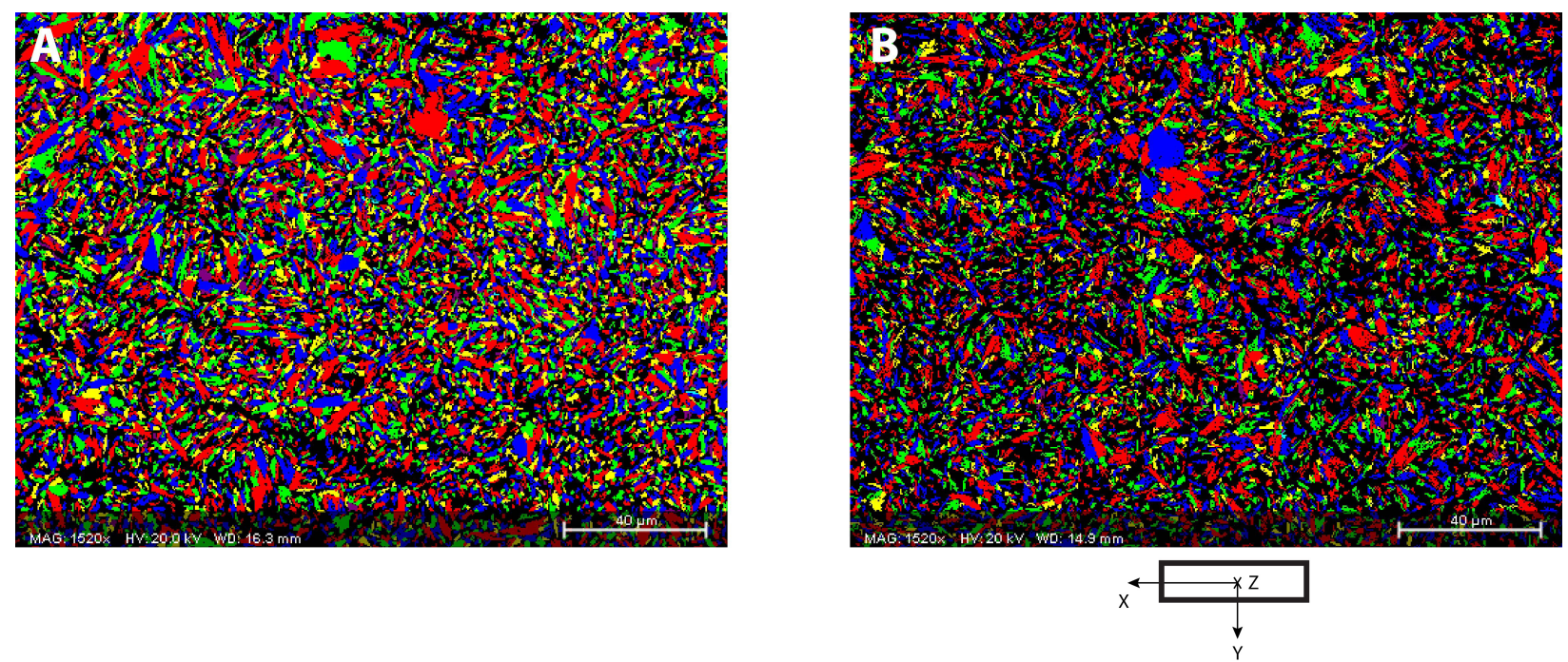

Figure 11: EBSD grain map of indexed martensite grains in samples quenched from $800^{\circ} \mathrm{C}$ for non treated (A) and (B) electric current treated samples.

At $900^{\circ} \mathrm{C}$ and $1000^{\circ} \mathrm{C}$, the pole figures (Figure 10) show that electric current treated samples are more randomly oriented, determined by distribution of mid-intensity MRD in the pole figure maps and the lower maximum MRD number. This evidence suggests the prior austenite grain size of electric current treated samples are by comparison refined, see Figures 12 and 13. Further to this, measurements of reconstructed prior austenite grains and calculations based on work by previous authors [22,25] show that the prior austenite in electric current treated steel are indeed refined Figure 14, in agreement with what was inferred from the pole figure data. The measured average prior austenite grain size for samples quenched from $1000^{\circ} \mathrm{C}$ are reduced by about $36.2 \%$ in electric current treated sample, the largest reduction for all quenched samples in percentage and absolute terms. The calculated grain sizes are more accurate and show that the measured values underestimate the average grain sizes for both treatment types, with and without electric current. Calculated values exhibit a similar trend, although the measured differences in grain sizes is less severe, and the largest reduction in grain size is $25.2 \%$ for samples quenched from $900^{\circ} \mathrm{C}$. A reduction in grain size is in direct contrast to what is expected of ohmic heating which may arise from an electric current passing through a conductor of finite resistance. This suggests that in the event there is indeed a degree of ohmic heating in the samples, it is dominated by another prevailing mechanism. 

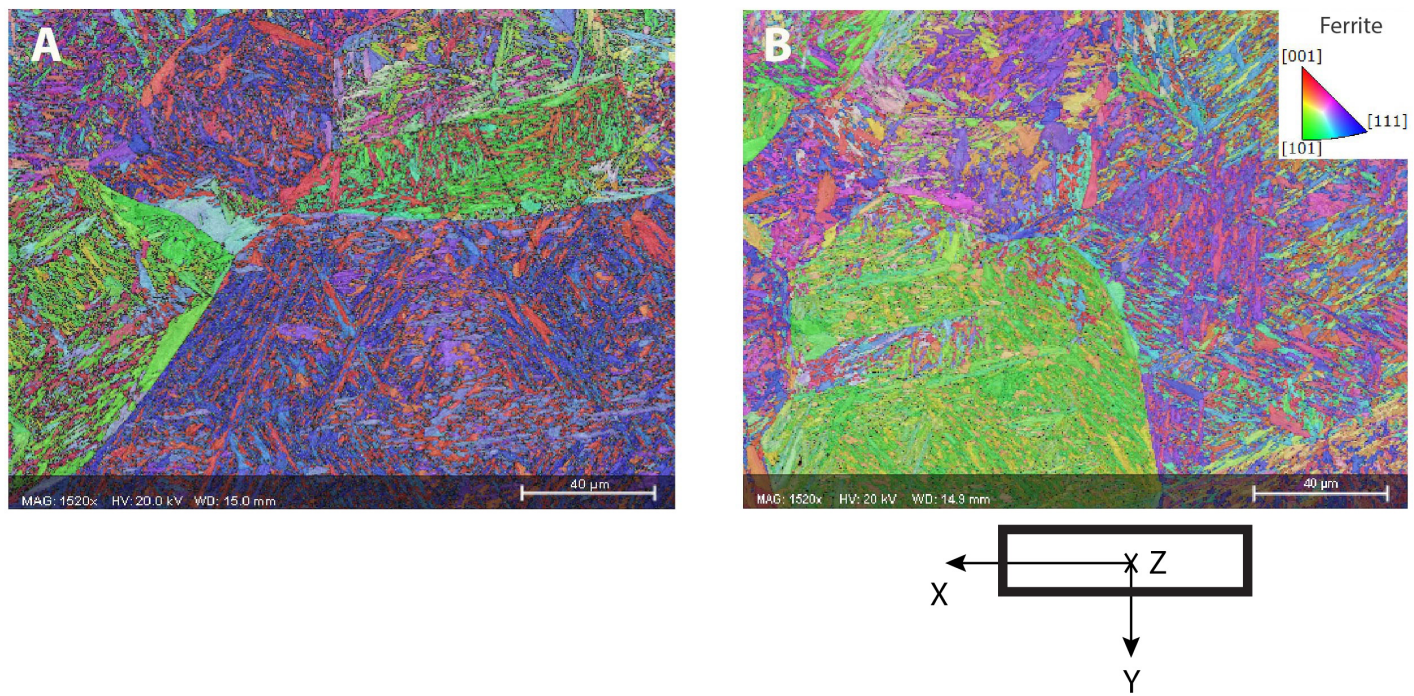

Figure 12: EBSD map, colour coded according to Inverse-Pole Figure (IPF) oriented with respect to the Z direction. Where the $\mathrm{Z}$ direction is normal to the plane of observation in the sample as indicated by the rod schematic below. For martensite quenched from $1000^{\circ} \mathrm{C}$ for non treated (A) and (B) electric current treated samples.
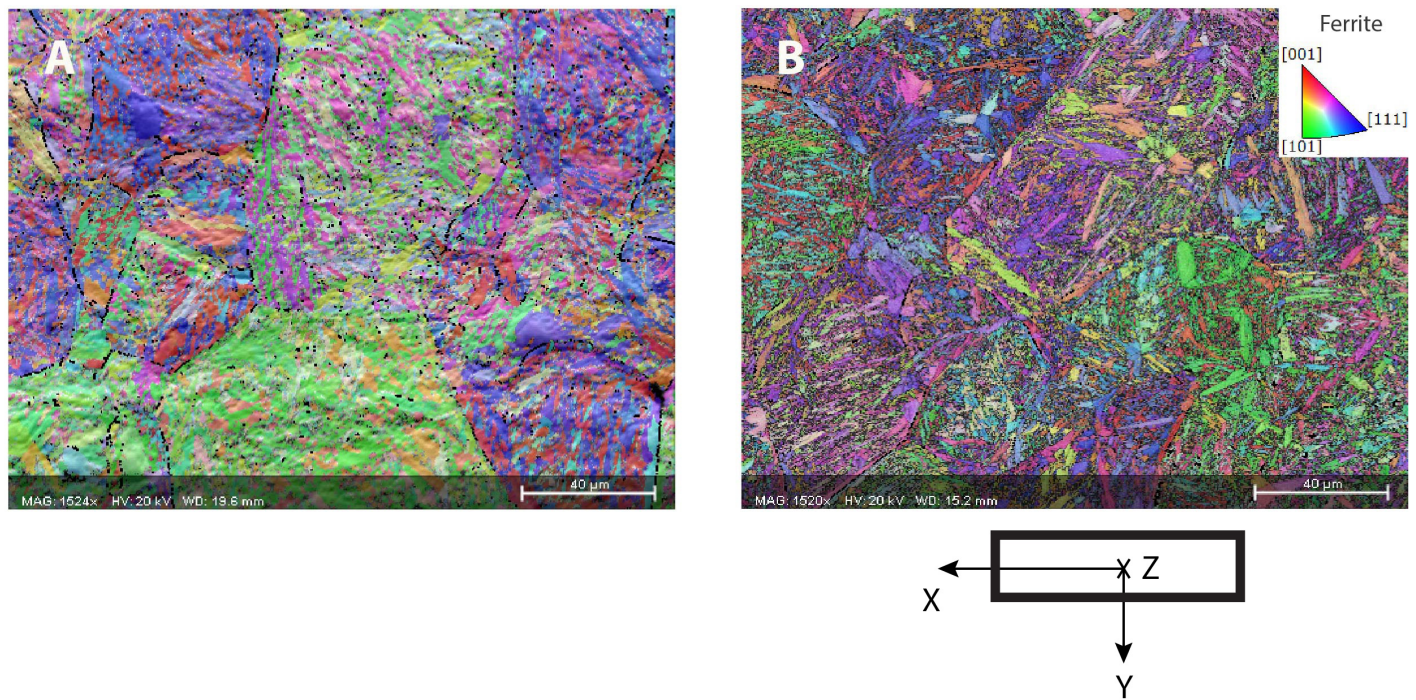

Figure 13: EBSD map, colour coded according to Inverse-Pole Figure (IPF) oriented with respect to the Z direction. Where the $\mathrm{Z}$ direction is normal to the plane of observation in the sample as indicated by the rod schematic below. For martensite quenched from $900^{\circ} \mathrm{C}$ for non treated (A) and (B) electric current treated samples. 


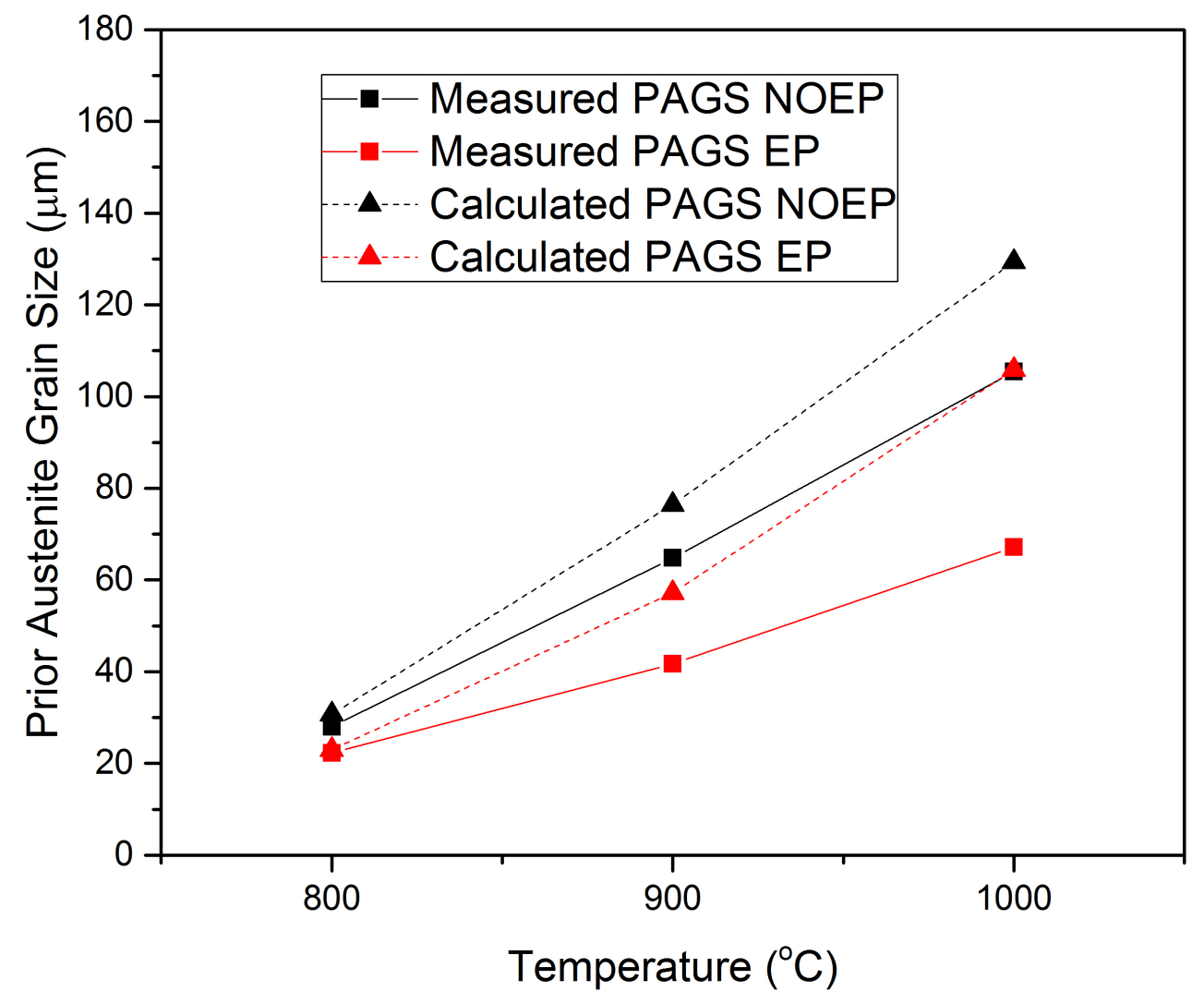

Figure 14: Measured and calculated prior austenite grain Sizes (PAGS) for samples quenched from $1000^{\circ} \mathrm{C}$, $900^{\circ} \mathrm{C}, 800^{\circ} \mathrm{C}$ for electric current treated (EP) and none treated (NOEP). Error bars of standard deviation of the mean are omitted for clarity, refer to Table 1 for the values.

\section{Conclusion}

Detailed consideration of angle misorientation distribution for martensite quenched from a range of temperatures reveals some of the influences of electric current treatment on austenite growth in a plain carbon steel. The 101 plane in austenite appears to grow preferentially along the applied current direction. Electric Current treatment further causes refinement of the prior austenite grains, which can be calculated from misorientation data, and inferred from orientation data generated by pole figures of the same area for increasing autenitisation temperatures. 


\section{Acknowledgements}

The authors are grateful for the joint support of the Engineering and Physical Sciences Research Council and Tata Steel under [grant number 1322018].

\section{References}

[1] O. Troitskii, V. Likhtman, The anisotropy of the action of electron and radiation on the deformation of zinc single crystal in the brittle state, Kokl. Akad. Nauk 8 (1963) 91.

[2] H. Conrad, N. Karam, S. Mannan, Effect of electric current pulses on the recrystallization of copper, Scripta Metallurgica 17 (3) (1983) 411-416.

[3] H. Conrad, Effects of electric current on solid state phase transformations in metals, Materials Science and Engineering: A 287 (2) (2000) 227-237.

[4] H. Conrad, K. Jung, Effects of an external electric field applied during the solution heat treatment of the Al-Mg-Si-Cu alloy AA6111, Zeitschrift für Metallkunde 95 (5) (2004) 352-355.

[5] X. Liao, Q. Zhai, J. Luo, W. Chen, Y. Gong, Refining mechanism of the electric current pulse on the solidification structure of pure aluminum, Acta Materialia 55 (9) (2007) 3103-3109.

[6] Y. Jiang, G. Tang, C. Shek, Y. Zhu, Z. Xu, On the thermodynamics and kinetics of electropulsing induced dissolution of Mg17Al12 phase in an aged Mg-9Al-1Zn alloy, Acta Materialia 57 (16) (2009) $4797-4808$.

[7] R. Zhu, G. Tang, S. Shi, M. Fu, Microstructure evolution of copper strips with gradient temperature in electropulsing treatment, Journal of Alloys and Compounds 581 (2013) 160-165.

[8] R. S. Qin, A. Rahnama, W. J. Lu, X. F. Zhang, B. Elliott-Bowman, Electropulsed steels, Materials Science and Technology 30 (9) (2014) 1040-1044.

[9] K. Okazaki, M. Kagawa, H. Conrad, A study of the electroplastic effect in metals, Scripta Metallurgica 12 (11) (1978) 1063-1068.

[10] K. S. Ralls, D. C. Ralph, R. A. Buhrman, Individual-defect electromigration in metal nanobridges, Phys. Rev. B 40 (17) (1989) 11561-11570.

[11] R. S. Qin, E. I. Samuel, a. Bhowmik, Electropulse-induced cementite nanoparticle formation in deformed pearlitic steels, Journal of Materials Science 46 (9) (2011) 2838-2842. 
[12] R. S. Qin, a. Bhowmik, Computational thermodynamics in electric current metallurgy, Materials Science and Technology 31 (13) (2014) 1560-1563.

[13] R. S. Qin, Critical Assessment 8: Outstanding issues in electropulsing processing, Materials Science and Technology 31 (2) (2015) 203-206.

[14] H. Conrad, Z. Guo, A. Sprecher, Effect of an electric field on the recovery and recrystallization of Al and $\mathrm{Cu}$, Scripta Metallurgica 23 (6) (1989) 821-823.

[15] W. J. Lu, X. F. Zhang, R. S. Qin, Stability of precipitates under electropulsing in 316L stainless steel, Materials Science and Technology 31 (13) (2015) 1530-1535.

[16] Z. S. Xu, Z. H. Lai, Y. X. Chen, Effect of electric current on the recrystallization behavior of cold worked $\alpha$ - Ti, Scripta Metallurgica 22 (2) (1988) 187-190.

[17] C. S. He, Y. D. Zhang, Y. N. Wang, X. Zhao, L. Zuo, C. Esling, Texture and microstructure development in cold-rolled interstitial free (IF) steel sheet during electric field annealing, Scripta Materialia 48 (6) (2003) 737-742.

[18] G. Hu, Y. Zhu, C. Shek, G. Tang, Electropulsing-induced G-texture evolution in a deformed Fe-3\%Si alloy strip, Journal of Materials Research 26 (07) (2011) 917-922.

[19] R. F. Zhu, J. N. Liu, G. Y. Tang, S. Q. Shi, M. W. Fu, Properties, microstructure and texture evolution of cold rolled $\mathrm{Cu}$ strips under electropulsing treatment, Journal of Alloys and Compounds 544 (2012) 203-208.

[20] X. Ye, G. Tang, G. Song, J. Kuang, Effect of electropulsing treatment on the microstructure, texture, and mechanical properties of cold-rolled Ti-6Al-4V alloy, Journal of Materials Research 29 (14) (2014) $1500-1512$.

[21] S. M. C. van Bohemen, Bainite and martensite start temperature calculated with exponential carbon dependence, Materials Science and Technology 28 (4) (2012) 487-495.

[22] L. Morales-Rivas, V. A. Yardley, C. Capdevila, C. Garcia-Mateo, H. Roelofs, F. G. Caballero, A procedure for indirect and automatic measurement of prior austenite grain size in bainite/martensite microstructures, Journal of Materials Science 50 (1) (2015) 258-267.

[23] J. K. Mackenzie, Second paper on statistics associated with the random distribution of cubes, Biometrika $45(1-2)(1958)$ 229-240. 
[24] D. Handscomb, On the random disorientation of two cubes, Can. J. Math 10 (1958) 85-88.

[25] A. Brahme, Y. Staraselski, K. Inal, R. K. Mishra, Determination of the minimum scan size to obtain representative textures by electron backscatter diffraction, Metallurgical and Materials Transactions A $43(13)(2012)$ 5298-5307.

[26] J. H. Pak, H. K. D. H. Bhadeshia, L. Karlsson, Mechanism of misorientation development within coalesced martensite, Materials Science and Technology 28 (8) (2012) 918-923.

[27] L. Germain, N. Gey, R. Mercier, P. Blaineau, M. Humbert, An advanced approach to reconstructing parent orientation maps in the case of approximate orientation relations: Application to steels, Acta Materialia 60 (11) (2012) 4551-4562.

[28] L. Helmick, S. J. Dillon, K. Gerdes, R. Gemmen, G. S. Rohrer, S. Seetharaman, P. A. Salvador, Crystallographic Characteristics of Grain Boundaries in Dense Yttria-Stabilized Zirconia Ceramic Product Development and Commercialization, Int. J. Appl. Ceram. Technol 8 (5) (2011) 1218-1228.

[29] H. Kitahara, R. Ueji, N. Tsuji, Y. Minamino, Crystallographic features of lath martensite in low-carbon steel, Acta Materialia 54 (5) (2006) 1279-1288. 